\title{
Further Possibilities for Linguistic Landscape Research
}

\section{Durk Gorter}

\section{Globalisation and the Spread of English}

The study of the linguistic landscape in its own right is a relatively recent development. In sociolinguistics and applied linguistics there is a growing interest as is evident from an increasing number of publications (see Backhaus this volume for a brief overview), of individual papers and of special colloquia at conferences. There are several reasons why it can be expected that a trend for more attention will persist in the near future. In this chapter some possibilities for further study of the linguistic landscape as a means to increase understanding of multilingualism will be highlighted.

In the foregoing chapters we have seen some examples of the study of the linguistic landscape in different parts of the world. We saw that although Japan is known as the prototype of a monolingual society, the linguistic landscape of Tokyo shows a surprising degree of multilingualism. Moreover, English has a high prestige there and its increasing presence in the visual scenery of the streets of Tokyo has become part of everyday Japanese life, as the study by Backhaus makes clear.

The importance of English as a global language is also highlighted in the metropolis of Bangkok, in Thailand, another part of Asia. Huebner's study demonstrates that the 'environmental print' of the streets in Bangkok is completely multilingual. In addition to this, his chapter documents the influence of English on the development of the Thai language system, not just in the form of lexical borrowing, but also in orthography, pronunciation and syntax. He thus provides evidence of a nascent Thai variety of English.

The chapter by Ben-Rafael and others on Israel shows that this country with relatively many recent immigrants also has a strong multilingual appearance. The Jewish population originates from many different countries whereas Palestinians constitute about $20 \%$ of all citizens. Hebrew is the official state language and it is omnipresent in the linguistic landscape in both Jewish and Israeli-Palestinian areas, except for the disputed locality of East Jerusalem. Arabic is the second official language and it dominates in East Jerusalem, but not in other parts. A Hebrew-Arabic pattern predominates among Palestinian-Israelis. English is also well-represented in the signs in the streets, mainly in a bilingual combination with either Hebrew or Arabic. The geographic distribution of the different population groups is reflected in a stronger or weaker presence of the language (Hebrew or Arabic) in the street image according to which group inhabits a certain area. English is overall gaining importance due to globalisation. According to Ben Rafael et al., English can better be called a 'non-foreign language'.

Multilingualism is an important aspect of all these studies, and at the same time the process of globalisation is made visible through the presence of English in the linguistic landscape. Next to globalisation there is also a process of 
regionalisation or localisation going on. Emphasis there is given to a regional identity and to a regional language. Together these processes have been called 'glocalisation'. The effects of these simultaneous processes can be seen in the streets of the towns of Ljouwert/Leeuwarden in Friesland and Donostia/San Sebastian in the Basque Country. In these regions in Europe a struggle for the survival of a minority language takes place. Frisian and Basque have been spoken in the area since 'time immemorial', but as minority languages they are threatened by the dominant state languages, Dutch and Spanish respectively. There are substantial differences between Friesland and the Basque Country. Frisian can be seen only to a modest degree in the linguistic landscape. Official language policy does not include the linguistic landscape, except for place names and street names. In contrast, in the Basque Country the promotion of the minority language in the linguistic landscape is an important part of language policy. Basque has obtained a substantial presence in the linguistic landscape, mainly side by side with Spanish, or in combination with, again, English. The linguistic landscape in the two cities of Ljouwert and Donostia seems surprisingly similar when it comes to the amount of English used on multilingual signs.

The studies as they have been presented in the earlier chapters do not just contribute to insight in the relative prominence of different languages as one sees them before ones eyes when strolling the shopping streets of these cities, but these studies also provide a better understanding of the spread of English. They are examples of what is possible now in the study of the linguistic landscape in relationship to gain more knowledge about multilingual phenomena.

\section{Terminology: Etymology and a Neologism}

In the Introduction to this volume the terminology and the semantics of the expression 'linguistic landscape' were discussed. An important point was made about the dictionary meaning of the word 'landscape', because it refers to a piece of scenery itself, as well as to the representation of the landscape. This duality of referral and representation is an important aspect of the different research projects at hand. The language signs in the cities can be taken as the literal panorama a spectator will see when walking the streets, but that same view reflects somehow the language composition of the inhabitants (and probably visitors) of the city. A sociological analysis of that representation can take different angles (see Ben Rafael et al.), but the texts can also be analysed according to their linguistic parameters (see Huebner).

The etymology of the word landscape and the use of the word in different languages are quite instructive in this context. The word landscape was first recorded in English in 1598. It is a loan from Dutch where it is a term used by painters who were around that time becoming famous for their skills in the landscape genre. The Dutch word landschap means 'region' or 'tract of land' but in the 16th century obtained artistic significance as 'a picture depicting a scenery on land', which meaning then was brought over into English. It took 34 years after the first recorded use of landscape in English until the word was used for natural scenery, the description of the direct landscape as we see it before us (see www.bartleby.com). 
The word for landscape is similar in the Germanic languages: Landschaft in German, landskab in Danish, landskap in Norwegian and Swedish and lânskip in Frisian. The root of the word landscape (land) was translated into the Romance languages as pays. The word was borrowed from the Northern countries to transfer the same double meaning of tract of land and a picture thereof. Thus the words paysage (French), paesaggio (Italian), paisaje (Spanish), paisagem (Portuguese), paisatge (Catalan) and peizaj (Romanian) (Lorzing, 2001: 28-29). Basque uses the loan from Spanish paisaia. Also the Finoergric languages Finnish (maisema) and Hungarian (tájkep) use the root 'land'. In Latvian it is ainava and in Lithuanian it is krastovaizdis. In Greek the word is topio referring to locus or site. In Slavic languages such as Polish (krajobraz) and Czech, Slovak and Slovene (krajina) the root for region or territory is used (kraj-). Serbian uses krajolik and the very similar Croatian nowadays prefers krajobraz. An exception is Russian which has both peyzazh and landshaft, which are loans from French and German. According to the landscape architect Lorzing (2001: 35) the first word peyzazh refers to the subjective aspect of landscape where the poetical, pictorial and emotional values are emphasised. The second meaning landschaft refers to an objective, technical approach, which makes it possible to change the landscape. These two dimensions, the more subjective emotional and the more objective technical, could also be used in studies of the linguistic landscape when it comes to distinguish between the dimensions of the symbolic or solidarity function and the informative or communicative function of language signs.

There is a similar understanding in all these languages in talking about 'a landscape' with its dual meaning of a tract of land as well as a painted representation. The linguistic landscape is then linked to both these qualities as it is the expression of written language before your eyes. A collection of signs with texts, however, is no so much encountered in the landscape in the literal sense, as found in the countryside, but much more inside urban areas. The number of linguistic tokens is especially high in shopping areas in cities. Therefore the word 'cityscape' might be introduced as a better term. It is a term that is already in use in the fields of cultural geography and urban development with an academic journal with 'Cityscape' as a its title. Since in most places the cityscape due to globalisation will not be monolingual, the term 'multilingual cityscape' would be the most precise. An objection against this neologism could be that it does not translate equally well into other languages.

\section{Technological Advancements}

Recent developments in digital camera technology make the study of the linguistic landscape possible at a relatively low cost. Of course, photography exists already over 150 years (with Daguerro types from the early 1840s), but to take large quantities of colour pictures was expensive and cumbersome until just a few years ago. The first professional digital camera dates from 1991 and such cameras arrived in the consumer market three years later. By 1996, 400,000 digital cameras were sold in the USA, against 15.6 million film cameras. In 2003 for the first time more digital than film cameras were sold and by 2005 these figures have almost reversed with an estimated 20.5 million digital cameras being sold (PMA Marketing Research, 2005:4). Cell phone cameras do add another dimension and 
will probably change the ways people take pictures and share them, wirelessly, with others.

Nowadays it is easy to collect, huge quantities of pictures. To store those pictures is no longer a problem with low cost storage devices and they can be stored on the web and shared with others (www.ofoto.com or www.flickr.com). Technology provides the means for new possibilities in the study of the linguistic landscape. The analysis of all those photographic data is an issue on which different angles can be taken. In the process of categorisation and interpretation the researcher (with the human eye) is still essential, but there are technological developments that can help with (semi-)automatic analysis.

Image processing and automatised analysis is a technical field which has not yet reached the study of linguistic landscape, but it may be of great relevance in the near future. Modern scanning techniques for microbiology, space research or medical purposes (CT, MRI, PET, etc.) result in new studies, also relevant for the field of language (e.g. already in studies of language production, bilingualism and language pathology). The human observer is fundamental to the advancement of image analysis, but computer systems and applications rapidly result in new insights into how humans see, perceive and know images (see for example Van den Broek, 2005). Further refinement of such techniques is expected in the near future and studies about visual communication and image representation can be of relevance for the study of texts in public space. Software for image analysis is commercially available by a firm such as Media Cybernetics (www.mediacy.com) but also in the public domain e.g. developed at the National Institute of Mental Health (NIMH) (http://rsb.info.nih.gov/nih-image/). There is good reason to believe that these tools can also be applied to study of the linguistic landscape.

An example of how this could work can be given by taking a look at the quite advanced technology of automatic number plate recognition (ANPR) alternatively referred to as licence plate recognition (LPR). This technology is able to identify car number plates with letters and numbers quickly and automatically. It is only very recently that this technology has come of age, but it is already in use for security, crime detection, traffic management and automatic payment systems at toll booths, car parks or petrol stations. When licence plates of many different countries and with many different styles can be recognised and 'deciphered' there is no reason why this could not be applied to most other signs that are visible in public spaces. The content analysis of signs could then be semi-automatised by connecting them to language databases.

\section{Regulation and Policy}

Governmental agencies regulate the use of signs to some extent and thus are part of what is categorised in the foregoing studies as 'top-down'. Some states, provinces or cities have developed more precise or far reaching legal measures than others. Among the more famous cases is the Charter of the French Language of 1977, better know as 'Bill 101' in Québec (Bourhis \& Landry, 2002). The bill required, among other things, that advertising be done in French alone and that all commercial signs be in French. Later these measures were relaxed and English is now acceptablef or the language of signs provided that French be given priority. Another well-known case is the so-called 'Toubon-law' introduced in 
France in 1994. The law insisted on the use of the French language in official government publications, advertisements, and other contexts in France. In Catalunya there is a legal obligation to have at least some presence of the Catalan language on all public and private signs. The linguistic landscape is closely monitored by the language policy department of the regional government. Studies have been done into the use of Catalan in displays of supermarkets, gas stations and Barcelona airport (e.g. Solé, 1997).

Traffic signs are usually an important part of the linguistic landscape and typically those signs are placed there by an official agency. Traffic signs have been under international considerational ready for a long time. How these signs are designed and regulated has some impact on the outcome of a study into the linguistic landscape. Hence the study of the linguistic landscape can derive a benefit from the work done by traffic sign designers. Their opinions on how signs function, what 'good' signs are, and which criteria are used for the production of signs can be of relevance.

The United Nations Economic Commission for Europe (UNECE) developed in 1968, and amended in 1995, the Vienna Convention on Road Signs and Signals in which it distinguishes eight different types of sign (e.g. danger warning signs, regulatory signs, mandatory signs). The goal is to come to international uniformity in order to facilitate international road traffic and to increase road safety (UNECE, 1968). In the USA the Federal Highway Administration (FHWA) publishes the Manual on Uniform Traffic Control Devices (MUTCD), as the national sign code that 'defines the standards used by road managers nationwide to install and maintain traffic control devices on all streets and highways'. (FHWA, 2003). The MUTCD focuses on minimum standards for size, height, and illumination. To ensure public safety, the MUTCD calls for bigger, taller, more obvious, and more frequent signage in areas where driver confusion can result in a traffic hazard. The Federal Highway Administration has been studying the understanding of the symbols, their legibility and conspicuity for years. These studies can also be of interest to the general study of the linguistic landscape. Criteria for designing signs will influence the text that will or can be used on them. Among these criteria comprehension, legibility and conspicuity stand out. A sign must be easy to understand, be readable from a distance and within a very short time, and be distinguished from other signs.

Among American sign regulators and designers there is an interesting debate going on between two perspectives. One view is that signs primarily serve an indexing function telling people what to find where or what to do or not to do. According to this view signs have to be regulated and limitations can be placed upon them for aesthetic reasons. Signs, including private and commercial signs, are seen as a form of land use activity and governmental planners should play a role in controlling them (Mandelker \& Ewald, 1988). The opposing view sees signs to 'serve multiple functions beyond indexing, including marketing, advertising, way-finding, providing information, building image, educating, and creating a visually stimulating retail environment' (Claus et al., 2004: 1). In this perspective larger and more conspicuous signs are more valuable. Signs are conceived of as speech rather than activity. Thus, signs can be 'shouting' or 'screaming' for attention and the economic value of a sign becomes an important issue. Different organisations have extensive information on that issue (e.g. 
Small Business Administration www.sba.gov, International Sign Association www.signs.org and the Signage Foundation www.signagefoundation.org). The Small Business Administration offers a handy definition of a sign as 'any visual display with words or symbols designed to convey information or attract attention'.

In bilingual countries or regions signage can also be of great symbolic importance and dispute. In particular the use of place names in a minority language or in the dominant state language has been a regular issue of linguistic conflict (Gorter, 1997; Hicks, 2002). In Brussels there exists an elaborate set of regulations on the use of both Dutch and French in street name signs, metro stations, etc. Painting over of signs with the 'wrong' names has been popular among language activists in many minority regions of Europe. This clearly tells passers by about the struggle over language rights and ensuing claims to the territory. Even when the central government officially regulates and accepts bilingual signs, the conflict over which place names to use and how they are placed on the signs may continue vehemently at a regional level as the case of the use of German or Slovenian in Carinthia, Austria has shown several times in recent years.

The highest density of signs can be found in cities and towns, in particular in the main shopping streets and industrial areas. The average number of signs per stretching metre can be rather high. Roadsides, in particular motorways, also have a lot of signs. In the countryside and in natural areas which are largely uninhabited, there are no, or only a very small number of, signs. In our world today there is little pure nature in a literal sense left because almost every spot has been 'touched' by human beings and traces of their presence have been left behind and with it linguistic tokens.

Many regulations try to limit the spread of signs in order to avoid the presence of an abundant linguistic landscape everywhere. In particular the sprawl over natural areas is an issue that gets attention of policy makers. The European Landscape Convention - better known as the Florence Convention (Council of Europe, 2000) which entered into force in March 2004, points to the importance of recognising the value and importance of landscapes, and of adopting measures to maintain and improve the quality of natural, rural but also of urban landscapes.

\section{Multiple Perspectives}

As the foregoing sections show linguistic landscape research can take more than one approach. The development of technology may influence its direction in the future as was indicated above. Multidisciplinary approaches from linguistic, sociological or sociolinguistic perspectives are also relevant for a better understanding of the linguistic landscape. Moreover, for instance, certain perspectives in psychology and geography can give us more insight into possibilities for a deeper knowledge of multilingualism. Psychological experiments in visual perception or studies of cityscapes in cultural geography do raise issues which are not dealt with in the chapters presented here, but which can also be of importance to the study of the linguistic landscape. The study of visual perception is a field of specialisation in its own right. Gombrich (1982) has applied sche- 
mata to works of art and his interpretations of those paintings can also be useful for certain features of the linguistic landscape.

The linguistic landscape is, of course, closely related to city planning as well. Is it however remarkable that scale models of newly developed cities usually do not contain any or at least few elements of the linguistic landscape. When such scale models have any references or examples at all, usually they are limited and stylised. In reality those new shopping centres or a new building in the city centre will be surrounded by numerous signs. The view and appreciation of such structures will be influenced by such textual displays. Even a popular computer game as 'Sim City', on the simulation of city life, has only a very limited number of signs. This feature is shared by so-called virtual worlds on the internet. Such worlds may seem in many respects like the real world, but they miss a linguistic landscape as a basic feature. Examples of such virtual worlds are Secondlife (http://secondlife.com), Paxlair (www.paxlair.com) or There (www.there.com). These worlds thus offer few opportunities for studying their linguistic environment. It would, however, be interesting to study which signs are there and the messages contained on them.

Furthermore it can be helpful to look at the field of semiotics: the study of the signs and symbols what they mean and how they are used. Several studies are already available on advertising and on commercials. In the case of linguistic street signs focus can be on the linguistic expressions and how it conveys a certain meaning, in particular to understand the social and cultural context in which the sign is placed. Scollon and Scollon (2003) have developed an overall approach to language on signs, referred to as 'geosemiotics'.

In the context of second language acquisition studies questions can be asked such as 'How is the linguistic landscape perceived by L2 users?', 'What is the role of the linguistic landscape as an additional source of language input? Or 'What attitudes do these L2 users have towards the linguistic landscape?' (Gorter \& Cenoz, 2004). It will also be worthwhile to explore in more detail linguistic processes of language contact, mixing and change as has been done in the chapter by Huebner. Signs in the linguistic landscape display different kinds of language contact phenomena either at the level of script, lexicon, morpheme or syntax.

The historical dimension of the linguistic landscape has not been explored in depth in the articles in this volume. Although Huebner has observed that the least amount of English is in the oldest neighbourhoods of Bangkok and the greatest amount in the 'Sky train', a light rail system, which he points to as 'the quintessence of modernity'. In another paper Backhaus (2005) uses the concept of 'layering' to dig out the diachronic development of some signs in the streets in Tokyo. His study shows that is can be valuable to take an historical angle andthen see how the linguistic landscape has evolved over a specific period of time. When one takes a look at pictures or postal cards of shopping streets from one hundred years ago, one sees fewer signs, although sometimes there are quite a few already. It is obvious that the number of linguistic signs has increased enormously in the inner cities of the world. How the landscape has evolved and how it changes, and what the importance is of such developments over time, is a matter for further study. Even though photographs have only recently become available on a massive scale, there are now some huge photo archives that can be searched by topic (e.g. by Associated Press 
(www.apimages.com), or collaborative collections with pictures of cities in the whole world such as www.worldcityphotos.org and www.fotopaises.com or the European Visual Archive (http://192.87.107.12/eva)).

To study the linguistic landscape is also to study cultural heritage. Languages are part of the cultural heritage and the sustainable development of linguistic diversity is seen as an important aspect of our heritage. According to the Unesco Universal Declaration on Cultural Diversity 'all persons have therefore the right to express themselves and to create and disseminate their work in the languages of their choice' (Unesco, 2002). The sustainability of cultural diversity is an important issue for policy development. Perhaps some models of environmental economics can contribute to the discovery of non-market benefits and the added value of the multilingualism, in order to understand better the ways in which the linguistic landscape is an important part of the preservation and the continued existence of different languages.

It will be clear that the study of the linguistic landscape can be done from multiple perspectives. The list could be elaborated further to include the fields of landscape architecture, communication studies, discourse studies as well as media and cultural studies and disciplines dealing with the theory, practice and aesthetics of visual design. All those fields can have a lot to tell us about signs. It looks promising to combine a number of these perspectives for a more inclusive approach to the study of multilingualism.

This multilingual reality dictates that studies of linguistic landscape should aim at discovering patterns in the underlying diversity. It is of utmost importance that theoretical models and approaches, such as proposed by Ben Rafael et al. (in this volume) are developed further. Studies of the linguistic landscape can become a major locus of scholarly activity in the coming decade if ideas taken from sociology, linguistics, social geography, psychology, economy, cognitive science, technology and the study of individual language use are combined.

In a thorough sense of the word, our world at the beginning of the 21st century is a multilingual one. The idea of monolingualism by country - one state, one language - has become obsolete and has been overtaken by a complicated interplay of many languages. Truly monolingual countries were always an exception, but globalisation with its ensuing migration flows, spread of cultural products, and high speed communication has led to more multilingualism in stead of less. There are many ways in which ethnic, sociocultural, religious and commercial diversity are related to linguistic diversity. The process of 'glocalisation' in the international arena leads to new expressions of cultural mix in music, food and clothing, but also in languages. Innumerable language contact situations cause a high incidence of multiple forms of bilingualism.

Given this multitude of languages around us it does not come as a surprise that an increasing number of scholars become interested in the study of the linguistic landscape. They share a common definition of what constitutes their object of their study: the visible language texts on signs in public space (Landry \& Bourhis, 1997), thus implicitly rejecting the much wider definitions of linguistic landscape sometimes used in the literature (see the Introduction to this volume). This concluding wanted to show that there are many possibilities for relevant and interesting linguistic landscape research that will help to improve our understanding of multilingual phenomena around the world. 


\section{References}

Backhaus, P. (2005) Signs of multilingualism in Tokyo: A diachronic look at the linguistic landscape. International Journal of the Sociology of Language 175/176, 103-121.

Bourhis R.Y. and Landry, R., (2002) La loi 101 et l'aménagement du paysage linguistique du Quebec. In P. Bouchard and R.Y. Bourhis (eds) (2002) L'aménagement Linguistique au Québec: 25 D'application de la Charte de la Lange Francaise (pp. 107-132). Québec: Publications du Québec.

Broek, E. van den (2005) Human-centered content-based image retrieval (PhD Thesis Radboud University Nijmegen) (at: http://eidetic.ai.ru.nl/egon/PhD-thesis) [November 2005].

Claus, R.J. et al. (2004) Street graphics and the law: A flawed perspective I \& II. In Signline (46\& 47) at http:/ / www.signs.org/Government/SignlineList.cfm [November 2005].

Council of Europe (2000) European Landscape Convention, Florence 20.X.2000. Strasbourg: Council of Europe. (http://conventions.coe.int: CETS 176) [November 2005].

FHWA (1997) Symbol signing design for older drivers. Publication No. FHWA-RD-94-069, July 1997 (at http://www.fhwa.dot.gov/tfhrc/safety/pubs/94069/94069.html) [November 2005].

Gombrich, E.H. (1982) The Image and the Eye (Further Studies in the Psychology of Pictorial Representation). London: Phaidon Press.

Gorter, D. (1997) Naamgeving in Friesland: Contact en conflict = consensus. In W. de Geest (ed.) Recente Studies in de Contactlinguïstiek, 35-45. Bonn: Dümmler.

Gorter, D. and J. Cenoz (2004) Linguistic landscapes and L2 learners in multilingual contexts. Paper at EUROSLA 14 (European Second Language Association Conference), 8-11 September 2004, San Sebastian/Donostia, Basque Country, Spain.

Hicks, D. (2002) Scotland's linguistic landscape: The lack of policy and planning with Scotland's place-names and signage. Paper at the World Congress on Language Policies, Barcelona April 2002 (www.linguapax.org/congres/taller/taller2/Hicks.html) [November 2005].

Landry, R. and Bourhis, R.Y. (1997) Linguistic landscape and ethnolinguistic vitality: An empirical study. Journal of Language and Social Psychology 6, 23-49.

Lorzing, Han (2001) The Nature of Landscape (a Personal Quest). Rotterdam: O10 Publishers.

Mandelker, D.R. and Ewald, W.R. $(1971,1988)$ Street Graphics and the Law. Chicago: American Planning Association

FHWA (Federal Highway Administration) (2003) MUTCD: Manual on Uniform Traffic Control Devices (under 23 Code of Federal Regulations (CFR), Part 655, Subpart F., at http:/ / mutcd.fhwa.dot.gov/index.htm [November 2005].

PMA Marketing Research (2005) Photo Industry 2005: Review and Forecast. Jackson, Michigan. (www.pmai.org) [November 2005].

Solé, J. (1997) La llengua de publicitat exterior a Barcelona l'any 1997. Barcelona: Generalitat de Catalunya, Direcció General de Política Lingüistica (Quaderns de Sociolingüistica), $28 \mathrm{pp}$.

UNECE (1968) United Nations Economic Commission for Europe Convention on Road Signs and Signals (done at Vienna on 8 November 1968. E/CONF.56/17/ Rev.1/Amend.1, at: www.unece.org/trans/conventn/signalse.pdf ) [November 2005].

Unesco (2002) Unesco Universal Declaration on Cultural Diversity. Adopted by the 31st Session of the General Conference, 2 November 2001, Paris, France. (at: http://unesdoc.unesco.org/images/0012/001271/127160m.pdf ) [November 2005]. 